\title{
Birth cohort, sex and educational disparities in the trajectories of body mass index in Taiwan: a longitudinal study
}

\author{
Tzu-Jung Wong ${ }^{1,2}$, Tsung Yu ${ }^{3^{*}}$, Ly-yun Chang ${ }^{4}$ and Xiang Qian Lao ${ }^{5}$
}

\begin{abstract}
Background: Taiwan has gone through rapid industrialization, urbanization and economic growth in the 20th and early 21 st centuries. Therefore, the population has experienced significant changes in the physical and social environment during the life course, which may affect the overall adiposity. Our aim was to examine the age trajectories of height, weight and body mass index (BMI) in the Taiwanese population and to explore the influences of sex, birth cohort and education.
\end{abstract}

Methods: The sample comprised 572,358 residents between 20 and 94years of age in Taiwan who attended at least one health examination during 1996 to 2017 in a cohort study. Repeated measures of body weight and height were collected using an auto-anthropometer. We conducted a series of linear mixed-effects growth curve models to examine the trajectory of height, weight, and BMI across the life course with stratification by sex.

Results: Age-related trajectories of BMI differed between men and women and stronger cohort effects were observed among men, with younger cohorts having higher BMI. After holding cohort and age variables constant, men with junior high or lower education were shorter, thinner and had higher BMI than men with university or higher education (effect sizes: $-3.138 \mathrm{~cm}, p<0.001 ;-2.277 \mathrm{~kg}, p<0.001 ; 0.121 \mathrm{~kg} / \mathrm{m}^{2}, p<0.001$, respectively). Women with junior high or lower education were shorter, heavier and had higher BMl than women with university or higher education (effect sizes: $-2.368 \mathrm{~cm}, p<0.001 ; 2.417 \mathrm{~kg}, p<0.001 ; 1.691 \mathrm{~kg} / \mathrm{m}^{2}, p<0.001$, respectively). The educational disparities in BMI were found to be larger among women.

Conclusions: Our findings suggest that younger generations, especially men, and lower educational level individuals, particularly women, have increasing levels of BMI. The influence of age and cohort effects together with sex and educational disparities on adiposity should be highlighted when designing future interventions and policies regarding overweight and obesity.

Keywords: Cohort effect, Education, Sex, Body mass index, Health disparities

\section{Background}

Body mass index (BMI) is an easy anthropometric measure that captures general adiposity and correlates with various chronic diseases and mortality [1]. Worldwide,

*Correspondence: tsungyu@mail.ncku.edu.tw

${ }^{3}$ Department of Public Health, College of Medicine, National Cheng Kung

University, 1 University Road, Tainan, Taiwan

Full list of author information is available at the end of the article age-related trajectories of BMI have been studied in multiple cohorts [2-7]. Recently, Yang and colleagues combined four large cohort studies in the United States (US): National Longitudinal Study of Adolescent to Adult Health, Midlife in the US study, Americans' Changing Lives Study, and the Health and Retirement Study, in which participants' age ranged from 11 to 90 years of age and older [8]. They conducted pooled integrative data 
analysis and showed that the trajectory of BMI increases in the US population steadily from adolescence to middle age at 40-60years and then decreases in later life, with variation in trajectories across different birth cohorts, sex, race and educational levels [8].

Since individuals from different birth cohorts may experience very diverse physical and social environments throughout their life course, most life course studies on the trajectories of BMI have found large birth cohort differences. A higher mean level of BMI and faster increase in BMI are often associated with more recent cohorts than earlier cohorts $[9,10]$. The secular change of physical and social environment is obvious for most countries. Over time, people have been exposed to an environment that becomes more obesogenic, such as living a life style with a high-calorie diet and low physical activity $[11,12]$.

Besides, social disparities in the trajectory of BMI are also of research interest. Women, lower socioeconomic status and minor racial/ethnic groups are often found to have a higher prevalence of overweight and obesity $[4,13]$. In their integrative data analysis, Yang et al. they showed that Hispanics and Blacks were associated with higher BMI than Whites [8]. When using parental and adulthood education as a marker for socioeconomic status, they found that a lower educational level was associated with higher BMI. Understanding the social disparities in BMI trajectories will help us identify their social determinants and design research and policies that target the most vulnerable groups.

Studies regarding the life course trajectories of BMI are scarce in Asian populations. Given that Taiwan has gone through rapid industrialization, urbanization and economic growth during the latter half of the twentieth century, there is a huge transition in the living environment and people's health behaviors [14]. We would expect that each birth cohort was exposed to its unique physical and social environment during their life course and that thereby each cohort perhaps has its unique pattern of trajectory of height, weight, and BMI. Moreover, it is unclear whether there are disparities in the trajectory of height, weight, and BMI between men and women as well as among different educational levels. Our aim was to examine these questions, using a large longitudinal health examination database in Taiwan.

\section{Methods}

\section{Study sample}

The Taiwan MJ cohort is a dynamic longitudinal study of health examination; the cohort profile and related studies using data from this cohort have been published previously [15-17]. Briefly, since 1994 the MJ Health Management Institution, a private company, provided fee-for-service standard health examination programs for residents in Taiwan. Members of the programs paid for their own health examination or were sponsored by their employers to attend periodic health examinations. At each clinical visit, participants underwent standard health examinations including physical examination, blood tests and urine tests and completed questionnaires regarding the information regarding sociodemographics, medical history, health behaviors, and lifestyle. The cohort included participants who provided informed consent for the use of their data for research purposes. During 1996 to 2017, 615,353 participants joined the programs, yielding 1,448,034 medical examinations. The present study was approved by the ethics board at the National Cheng Kung University in Tainan, Taiwan (A-ER-108-081).

Our study sample included 597,924 participants aged 20-94 years who had at least one health examination from 1996 to 2017. Among them, 25,566 participants had missing information regarding their educational levels. We excluded these participants, resulting in a sample of 572,358 participants $(273,879$ men and 298,479 women). Each participant could have more than one visit to the M) Health Management Institution; the number of visits ranged from one to 34 . Most participants had only one $(n=311,306,54.4 \%)$ or two $(n=104,934,18.3 \%)$ health examination visits (data points) during 1996 to 2017.

\section{Measures \\ Dependent variables}

The anthropometric data, including body weight and body height, were measured by auto-anthropometer in the MJ Health Management Institution (KN-5000A; Nakamura, Tokyo, Japan). Weight was measured without shoes and with participants wearing light indoor clothing and was recorded to the nearest $0.1 \mathrm{~kg}$. Height was measured and recorded to the nearest $0.1 \mathrm{~cm}$. BMI was calculated using weight $(\mathrm{kg})$ divided by the square of height ( $\mathrm{m})$.

\section{Independent variables}

Participants were queried in the questionnaire about their highest educational level. There were seven categories: (1) Some elementary school (<6years), (2) Elementary school (6years), (3) Junior high school (9years), (4) Senior high school (12 years), (5) College (14years), (6) University (16years) and (7) Graduate school or higher (>16years). For simplicity, in the analysis we categorized educational levels into three: (1) Junior high school or lower ( $\leq 9$ years), (2) Senior high school/college (10-15 years), and (3) University or higher ( $\geq 16$ years). We defined nine categories of birth cohort: (1) before 1920, (2) 1920-1929, (3) 1930-1939, (4) 1940-1949, (5) 
1950-1959, (6) 1960-1969, (7) 1970-1979 (8) 19801989, and (9) after 1990.

\section{Statistical analysis}

To examine the association of age and birth cohort with height, weight, and BMI, we plotted the mean values of height, weight, and BMI against age in years with stratification by birth cohort and sex. We used linear mixedeffects growth curve models for data analysis to examine the trajectory of height, weight, and BMI across the life course. Linear mixed-effects growth curve models can deal with data that are unbalanced in time [18]; therefore, these models are particularly suitable for our data that were collected using a dynamic cohort study design where each participant had a different number of visits. To maximize data points in our analysis, we included all participants regardless of the number of visits they contributed to the study. Given the distinct patterns of age trajectory between the sexes, we conducted the analysis separately for men and women. Linear mixed-effects growth curve analysis was performed using the xtmixed command in Stata 15 (StataCorp LLC, College Station, TX, USA).

The level-one linear mixed-effects growth curve model included the intercept $\left(\beta_{0 i}\right)$ and two terms for the age trajectory (linear slope $\beta_{1 i}$ and quadratic slope $\beta_{2 i}$ ):

$$
Y_{t i}=\beta_{0 i}+\beta_{1 i} A g e_{t i}+\beta_{2 i} A g e_{t i}^{2}+e_{t i}
$$

where $Y_{t i}$ is the weight, height, or BMI value for subject $i$ at visit $t$. There were 572,358 participants and the maximal number of visit was 34. Age $e_{t i}$ was the age of participant $i$ at visit $t$ and is centered at 45 years. $e_{t i}$ is the within-subject error term (residual).

The level-two linear mixed-effects growth curve model incorporated each participant's specific characteristics predictors for the age trajectory (as fixed effect) and between-subject variation (as random effects).

For the intercept: $\beta_{0 i}=\gamma_{00}+\gamma_{01}$ education $_{i}+\gamma_{02}$ cohort $_{i}$ $+u_{0 i}$;

for the linear slope: $\beta_{1 i}=\gamma_{10}+\gamma_{11}$ education $_{i}+\gamma_{12}$ cohor $t_{i}+u_{1 i}$;

for the quadratic slope: $\beta_{2 i}=\gamma_{20}+\gamma_{21}$ education $_{i}+\gamma_{22} \mathrm{co}$ hort $_{i}+u_{2 i}$,

where $\gamma_{01}, \gamma_{11}$ and $\gamma_{21}$ represented the effect of education on the intercept and slope and $\gamma_{02}, \gamma_{12}$ and $\gamma_{22}$ represented the effect of the birth cohort. Both educational level and birth cohort were coded using dummy variables. $u_{0 i}, u_{1 i}$ and $u_{2 i}$ were random effects terms that captured the variation between participants.

To ease the interpretation of the coefficients estimated in the linear mixed-effects growth curve models, we also plotted the predicted mean values for the subjects grouped by sex, birth cohort, and educational levels. These graphs helped us better examine the effect of birth cohort and education on the age trajectory of height, weight, and BMI.

\section{Results}

Table 1 shows the descriptive characteristics of the study sample at baseline. Men accounted for $47.9 \%$ $(273,879 / 572358)$ of the sample. Mean \pm standard deviation of age at baseline were $40.1 \pm 13.4$ years for men and $40.1 \pm 13.5$ years for women. Most of the study participants were from the 1950-1959 (15.8\%), 1960-1969 (24.1\%), and 1970-1979 (28.1\%) birth cohorts. The distribution of educational levels is also listed in Table 1 by sex, and suggests that men in our sample had higher educational levels than women; $42.9 \%$ of men and $32.6 \%$ of women attained a university degree or higher. The mean height, weight, and BMI were higher in men $(170.0 \mathrm{~cm}$, $69.6 \mathrm{~kg}$ and $24.1 \mathrm{~kg} / \mathrm{m}^{2}$, respectively) than in women $\left(157.5 \mathrm{~cm}, 55.0 \mathrm{~kg}\right.$ and $22.2 \mathrm{~kg} / \mathrm{m}^{2}$, respectively).

Figure 1 shows the trajectories of mean height, weight and BMI by birth cohorts for men and women. The trajectories of height suggest that as individuals aged in time, the mean height decreased slightly. By comparing different birth cohorts, the younger cohorts had higher mean height values than the older cohorts (see Fig. 1A and B). The trajectories of weight for men suggest that the mean weight increased from young adulthood to about 50 years of age and then declined. Younger birth cohorts had higher mean weight values than older birth cohorts (see Fig. 1C). However, the weight trajectory pattern was different for women. The mean weight for women increased from young adulthood to about age 60 and then declined. The differences in mean weight among birth cohorts were lower for women than for men (see Fig. 1D). The trajectories of BMI for men suggest that the mean BMI increased from young adulthood to about age 50 and then levelled off. Younger birth cohorts also had higher mean BMI values than older birth cohorts (see Fig. 1E). The trajectories of BMI for women increased from young adulthood to about age 70 and then levelled off; the differences in BMI values among birth cohorts for women were not as evident as that for men (see Fig. 1F).

Tables 2 and 3 display the coefficients from the linear mixed-effects models of height, weight and BMI among men and women. To ease the interpretation, we used these coefficients to generate graphs of predicted mean trajectories by educational levels (three categories) for men and for women (see Fig. 2). For purposes of illustration, we only graphed the data for birth cohorts of 19201929, 1950-1959, and 1980-1989. For height, there were educational disparities for both men and women (see Fig. 2A and B). In the model for men (see Table 2), 
Table 1 Baseline characteristics of study sample

\begin{tabular}{|c|c|c|}
\hline Characteristics & Men $(n=273,879)$ & Women $(n=298,479)$ \\
\hline Age (year), mean $\pm S D$ & $40.11 \pm 13.35$ & $40.09 \pm 13.48$ \\
\hline \multicolumn{3}{|l|}{ Birth cohort (\%) } \\
\hline Before 1920 & 0.30 & 0.22 \\
\hline 1920-1929 & 2.62 & 1.94 \\
\hline 1930-1939 & 6.43 & 6.56 \\
\hline 1940-1949 & 9.52 & 11.68 \\
\hline 1950-1959 & 15.23 & 16.28 \\
\hline 1960-1969 & 25.58 & 22.65 \\
\hline 1970-1979 & 28.50 & 27.73 \\
\hline 1980-1989 & 10.85 & 11.87 \\
\hline After 1990 & 0.97 & 1.07 \\
\hline \multicolumn{3}{|l|}{ Education (\%) } \\
\hline Some elementary school & 1.02 & 5.89 \\
\hline Elementary school & 9.09 & 14.22 \\
\hline Junior high school & 6.30 & 6.62 \\
\hline Senior high school & 20.38 & 22.26 \\
\hline College & 20.32 & 18.40 \\
\hline University & 28.09 & 25.65 \\
\hline Graduate school or higher & 14.80 & 6.97 \\
\hline Height $(\mathrm{cm})$, mean $\pm S D$ & $169.96 \pm 6.49$ & $157.50 \pm 5.88$ \\
\hline Weight $(\mathrm{kg})$, mean $\pm S D$ & $69.56 \pm 11.39$ & $54.96 \pm 9.08$ \\
\hline Body mass index $\left(\mathrm{kg} / \mathrm{m}^{2}\right)$, mean $\pm S D$ & $24.05 \pm 3.47$ & $22.19 \pm 3.66$ \\
\hline
\end{tabular}

SD standard deviation

holding the cohort and age variables constant, men with junior high school or lower education were $3.138 \mathrm{~cm}$ $(p<0.001)$ shorter than men with university or higher education. Men with high school/college education were $0.963 \mathrm{~cm}(p<0.001)$ shorter than men with university or higher education. In the models for women (see Table 3 ), women with junior high school or lower education and women with high school/college education were also shorter than women with a university or higher education (effect size: $-2.368, p<0.001$ and $-0.664, p<0.001$, respectively).

For weight, Fig. 2C and D also suggest educational disparities, but the direction was reverse when comparing men versus women. In the model for men (see Table 2), men with junior high school or lower education and men with high school/college education were lighter than men with university or higher education (effect size: -2.277 , $p<0.001$ and $-0.489, p<0.001$, respectively). But in the model for women (see Table 3), women with junior high school or lower education and women with high school/ college education were heavier than women with university or higher education (effect size: 2.417, $p<0.001$ and $0.672, p<0.001$, respectively). We found that women with junior high school or lower education had a faster decline in weight after age 70 .
For BMI, the educational disparities were greater in women than in men (see Fig. 2E and F). Men with junior high school or lower education and men with high school/college education had higher BMI values than men with university or higher education (see Table 2, effect size: $0.121, p<0.001$ and $0.117, p<0.001$, respectively). Women with junior high school or lower education and women with high school/college education also had higher BMI values than women with university or higher education (see Table 3, effect size: 1.691, $p<0.001$ and $0.471, p<0.001$, respectively).

\section{Discussion}

Our study had some noteworthy findings. First, the agerelated patterns for the trajectories of weight and BMI were shown and differed between men and women. The mean weight and BMI increased and peaked at an older age in women (60-70years) than in men (40-50years). Second, there was evidence of cohort effects on the trajectories of height, weight, and BMI in the Taiwanese adults born from 1920 to 1990 . Over secular time, the mean height, weight, and BMI had increased, and the cohort effects were more evident for men than for women. Third, education had distinct influences on the trajectories of weight and BMI. Lower educational levels were associated with lower weight 
Men

A

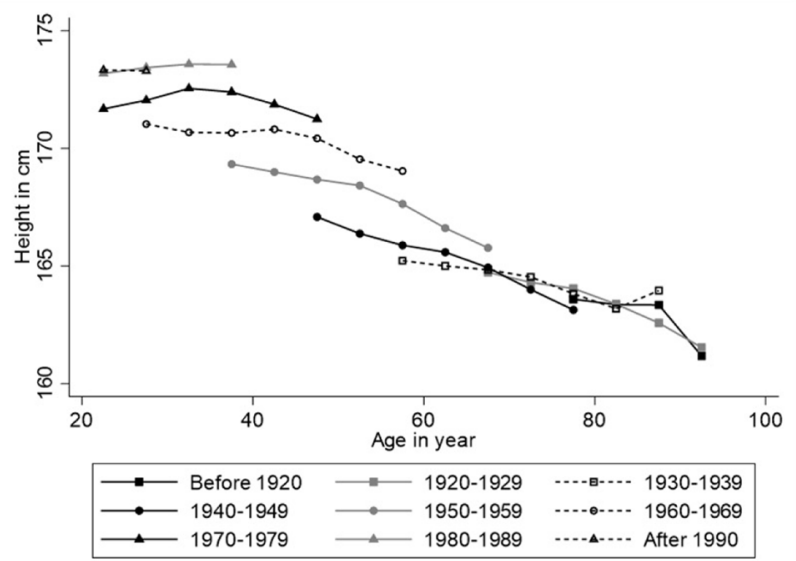

C

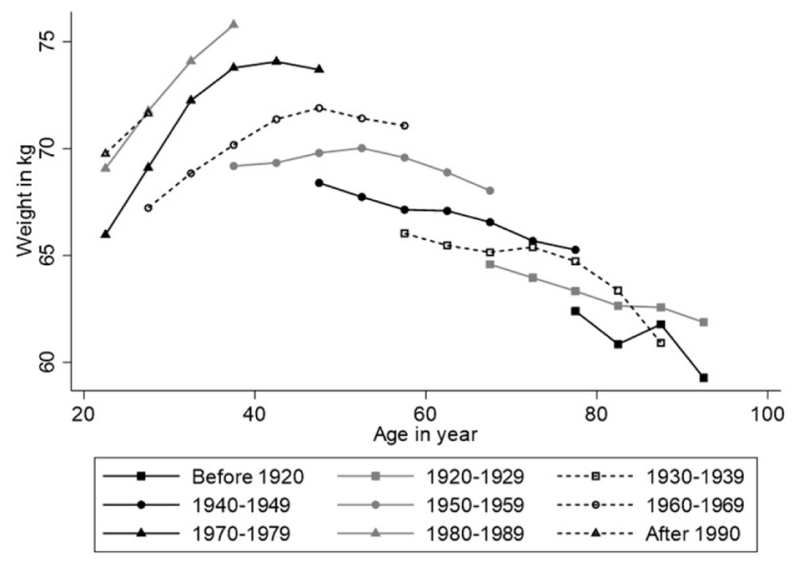

E

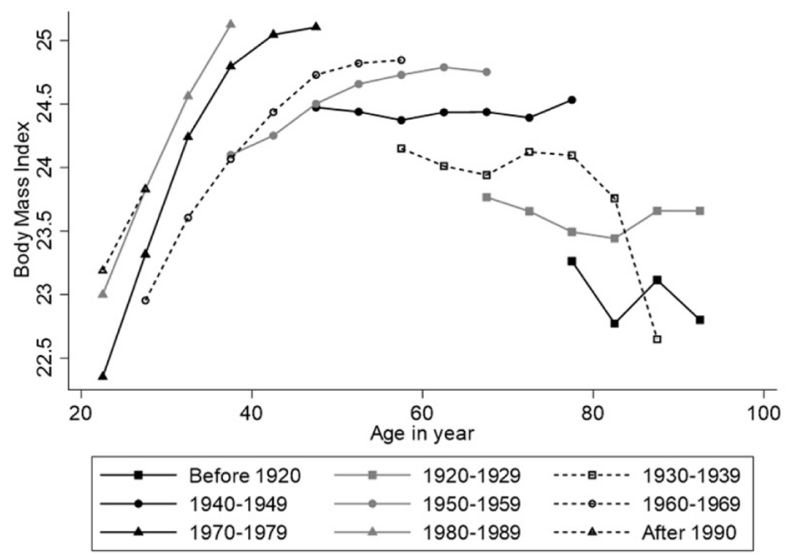

Women

B

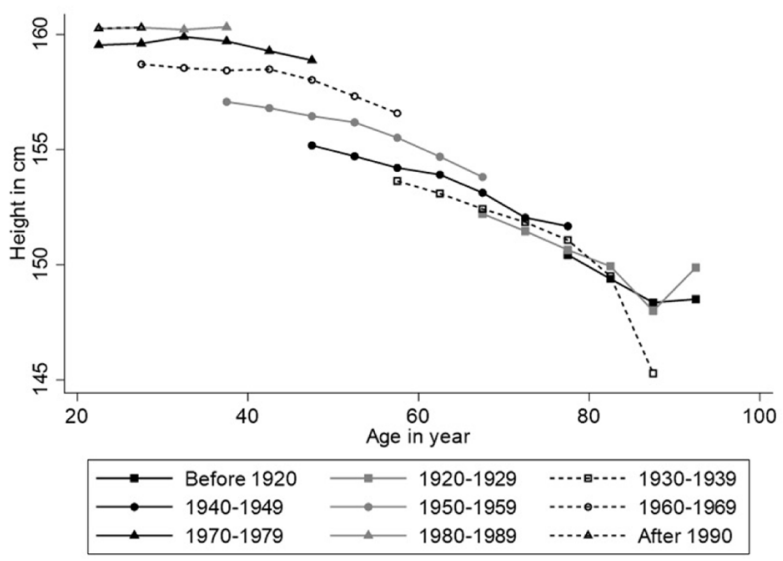

D

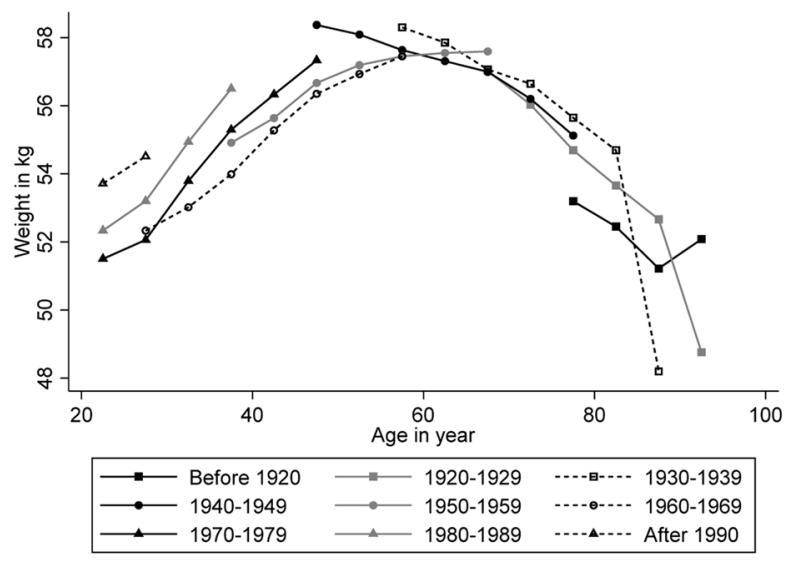

$\mathbf{F}$

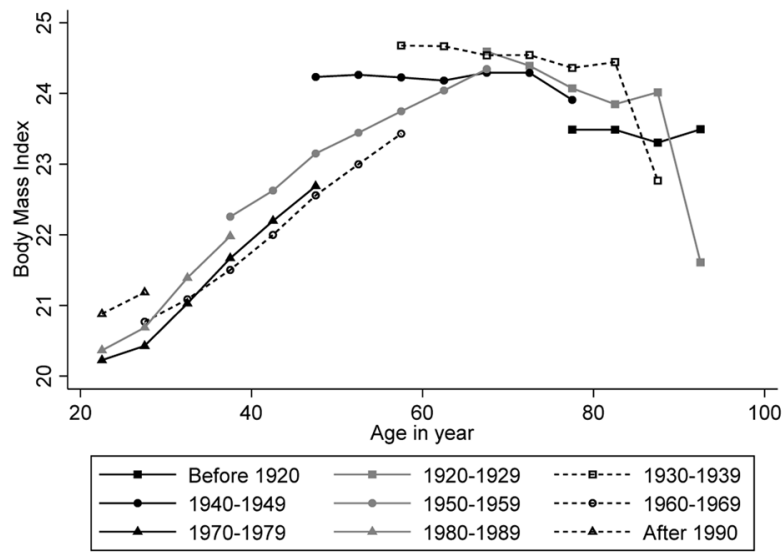

Fig. 1 (A) Mean height trajectories by birth cohort for men. (B) Mean height trajectories by birth cohort for women. (C) Mean weight trajectories by birth cohort for men. (D) Mean weight trajectories by birth cohort for women. (E) Mean BMl trajectories by birth cohort for men. (F) Mean BMI trajectories by birth cohort for women. BMI= body mass index 
Table 2 Linear mixed-effects growth-curve models for men

\begin{tabular}{|c|c|c|c|c|c|c|}
\hline & \multicolumn{2}{|l|}{ Height } & \multicolumn{2}{|l|}{ Weight } & \multicolumn{2}{|l|}{ BMI } \\
\hline & Coefficient & $P$-value & Coefficient & $P$-value & Coefficient & $P$-value \\
\hline \multicolumn{7}{|l|}{ Fixed effect parameters } \\
\hline \multicolumn{7}{|l|}{ For intercept $\left(\boldsymbol{\beta}_{0 i}\right)$} \\
\hline Intercept & 171.173 & $<0.001$ & 72.623 & $<0.001$ & 24.767 & $<0.001$ \\
\hline Education $=\mathrm{JHS}$ or lower & -3.138 & $<0.001$ & -2.277 & $<0.001$ & 0.121 & $<0.001$ \\
\hline Education $=\mathrm{HS} /$ college & -0.963 & $<0.001$ & -0.489 & $<0.001$ & 0.117 & $<0.001$ \\
\hline Education $=U$ or higher & Reference & & & & & \\
\hline Cohort= before 1920 & -8.143 & 0.009 & -10.806 & 0.427 & -2.448 & 0.591 \\
\hline Cohort $=1920-1929$ & -6.275 & $<0.001$ & -7.970 & $<0.001$ & -1.051 & 0.047 \\
\hline Cohort = 1930-1939 & -4.271 & $<0.001$ & -6.264 & $<0.001$ & -0.966 & $<0.001$ \\
\hline Cohort = 1940-1949 & -3.302 & $<0.001$ & -4.730 & $<0.001$ & -0.724 & $<0.001$ \\
\hline Cohort $=1950-1959$ & -1.593 & $<0.001$ & -2.347 & $<0.001$ & -0.371 & $<0.001$ \\
\hline Cohort = 1960-1969 & Reference & & & & & \\
\hline Cohort = 1970-1979 & 1.153 & $<0.001$ & 2.844 & $<0.001$ & 0.646 & $<0.001$ \\
\hline Cohort = 1980-1989 & 2.390 & $<0.001$ & 5.857 & $<0.001$ & 1.219 & $<0.001$ \\
\hline Cohort=After 1990 & 6.254 & $<0.001$ & 16.950 & 0.042 & 4.758 & 0.088 \\
\hline \multicolumn{7}{|l|}{ For linear slope $\left(\boldsymbol{\beta}_{1 i}\right)$} \\
\hline Intercept & -0.043 & $<0.001$ & 0.134 & $<0.001$ & 0.060 & $<0.001$ \\
\hline Education $=\mathrm{JHS}$ or lower & -0.009 & $<0.001$ & -0.007 & 0.237 & 0.005 & 0.009 \\
\hline Education $=\mathrm{HS} /$ college & -0.004 & $<0.001$ & 0.010 & 0.001 & 0.006 & $<0.001$ \\
\hline Education $=U$ or higher & Reference & & & & & \\
\hline Cohort= before 1920 & 0.375 & 0.019 & 0.164 & 0.816 & 0.003 & 0.989 \\
\hline Cohort $=1920-1929$ & 0.271 & $<0.001$ & 0.056 & 0.595 & -0.056 & 0.112 \\
\hline Cohort = 1930-1939 & 0.141 & $<0.001$ & -0.038 & 0.274 & -0.060 & $<0.001$ \\
\hline Cohort $=1940-1949$ & 0.074 & $<0.001$ & -0.024 & 0.124 & -0.033 & $<0.001$ \\
\hline Cohort $=1950-1959$ & 0.038 & $<0.001$ & 0.019 & 0.002 & -0.005 & 0.017 \\
\hline Cohort = 1960-1969 & Reference & & & & & \\
\hline Cohort = 1970-1979 & -0.053 & $<0.001$ & -0.194 & $<0.001$ & -0.047 & $<0.001$ \\
\hline Cohort $=1980-1989$ & 0.009 & 0.241 & -0.060 & 0.147 & -0.027 & 0.048 \\
\hline Cohort=After 1990 & 0.322 & 0.048 & 0.748 & 0.326 & 0.235 & 0.357 \\
\hline \multicolumn{7}{|l|}{ For quadratic slope $\left(\boldsymbol{\beta}_{2 i}\right)$} \\
\hline Intercept & -0.004 & $<0.001$ & -0.012 & $<0.001$ & -0.003 & $<0.001$ \\
\hline Education $=\mathrm{JHS}$ or lower & 0.000 & $<0.001$ & 0.001 & $<0.001$ & 0.000 & 0.517 \\
\hline Education $=\mathrm{HS} /$ college & 0.000 & 0.273 & 0.000 & 0.613 & 0.000 & 0.573 \\
\hline Education $=U$ or higher & Reference & & & & & \\
\hline Cohort= before 1920 & -0.004 & 0.082 & 0.004 & 0.690 & 0.001 & 0.661 \\
\hline Cohort = 1920-1929 & -0.002 & $<0.001$ & 0.005 & 0.004 & 0.002 & $<0.001$ \\
\hline Cohort = 1930-1939 & -0.001 & $<0.001$ & 0.008 & $<0.001$ & 0.003 & $<0.001$ \\
\hline Cohort = 1940-1949 & 0.000 & 0.970 & 0.007 & $<0.001$ & 0.002 & $<0.001$ \\
\hline Cohort = 1950-1959 & 0.000 & 0.556 & 0.004 & $<0.001$ & 0.001 & $<0.001$ \\
\hline Cohort = 1960-1969 & Reference & & & & & \\
\hline Cohort = 1970-1979 & -0.001 & $<0.001$ & -0.011 & $<0.001$ & -0.003 & $<0.001$ \\
\hline Cohort = 1980-1989 & 0.002 & $<0.001$ & -0.005 & $<0.001$ & -0.002 & $<0.001$ \\
\hline Cohort=After 1990 & 0.008 & 0.024 & 0.012 & 0.478 & 0.004 & 0.544 \\
\hline \multicolumn{7}{|l|}{ Random effects parameters } \\
\hline Intercept $\left(\boldsymbol{u}_{0 i}\right)$ & 33.597 & & 120.480 & & 11.174 & \\
\hline Linear slope $\left(\boldsymbol{u}_{1 i}\right)$ & 0.002 & & 0.129 & & 0.015 & \\
\hline Quadratic slope $\left(\boldsymbol{u}_{2 i}\right)$ & 0.000 & & 0.000 & & 0.000 & \\
\hline Residual $\left(\boldsymbol{e}_{t i}\right)$ & 0.213 & & 4.312 & & 0.504 & \\
\hline
\end{tabular}

JHS junior high school; $H S$ high school; U University 
Table 3 Linear mixed-effects growth-curve models for women

\begin{tabular}{|c|c|c|c|c|c|c|}
\hline & \multicolumn{2}{|l|}{ Height } & \multicolumn{2}{|l|}{ Weight } & \multicolumn{2}{|l|}{ BMI } \\
\hline & Coefficient & $P$-value & Coefficient & $P$-value & Coefficient & $P$-value \\
\hline \multicolumn{7}{|l|}{ Fixed effect parameters } \\
\hline \multicolumn{7}{|l|}{ For intercept $\left(\boldsymbol{\beta}_{0 i}\right)$} \\
\hline Intercept & 158.875 & $<0.001$ & 55.764 & $<0.001$ & 22.092 & $<0.001$ \\
\hline Education $=\mathrm{JHS}$ or lower & -2.368 & $<0.001$ & 2.417 & $<0.001$ & 1.691 & $<0.001$ \\
\hline Education = HS/college & -0.664 & $<0.001$ & 0.672 & $<0.001$ & 0.471 & $<0.001$ \\
\hline Education $=U$ or higher & Reference & & & & & \\
\hline Cohort= before 1920 & -1.182 & $<0.001$ & -1.061 & 0.414 & -0.251 & 0.628 \\
\hline Cohort $=1920-1929$ & -4.743 & $<0.001$ & 2.234 & 0.222 & 2.201 & 0.003 \\
\hline Cohort = 1930-1939 & -3.947 & $<0.001$ & 0.158 & 0.631 & 1.195 & $<0.001$ \\
\hline Cohort = 1940-1949 & -2.709 & $<0.001$ & 0.381 & $<0.001$ & 0.927 & $<0.001$ \\
\hline Cohort $=1950-1959$ & -1.340 & $<0.001$ & -0.318 & $<0.001$ & 0.229 & $<0.001$ \\
\hline Cohort = 1960-1969 & Reference & & & & & \\
\hline Cohort = 1970-1979 & 0.757 & $<0.001$ & 2.533 & $<0.001$ & 0.797 & $<0.001$ \\
\hline Cohort = 1980-1989 & 1.100 & $<0.001$ & 7.791 & $<0.001$ & 2.734 & $<0.001$ \\
\hline Cohort=After 1990 & 7.892 & $<0.001$ & 24.465 & 0.001 & 7.895 & 0.006 \\
\hline \multicolumn{7}{|l|}{ For linear slope $\left(\boldsymbol{\beta}_{1 i}\right)$} \\
\hline Intercept & -0.045 & $<0.001$ & 0.234 & $<0.001$ & 0.108 & $<0.001$ \\
\hline Education $=\mathrm{JHS}$ or lower & 0.002 & 0.203 & 0.003 & 0.472 & 0.008 & $<0.001$ \\
\hline Education $=\mathrm{HS} /$ college & 0.000 & 0.639 & 0.003 & 0.382 & 0.003 & 0.019 \\
\hline Education $=U$ or higher & Reference & & & & & \\
\hline Cohort = before 1920 & 0.295 & $<0.001$ & -0.086 & 0.307 & -0.090 & 0.007 \\
\hline Cohort $=1920-1929$ & 0.165 & $<0.001$ & -0.339 & 0.006 & -0.187 & $<0.001$ \\
\hline Cohort = 1930-1939 & 0.148 & $<0.001$ & -0.217 & $<0.001$ & -0.135 & $<0.001$ \\
\hline Cohort $=1940-1949$ & 0.096 & $<0.001$ & -0.238 & $<0.001$ & -0.131 & $<0.001$ \\
\hline Cohort $=1950-1959$ & 0.046 & $<0.001$ & -0.086 & $<0.001$ & -0.048 & $<0.001$ \\
\hline Cohort = 1960-1969 & Reference & & & & & \\
\hline Cohort = 1970-1979 & -0.045 & $<0.001$ & 0.150 & $<0.001$ & 0.071 & $<0.001$ \\
\hline Cohort $=1980-1989$ & -0.022 & 0.005 & 0.579 & $<0.001$ & 0.229 & $<0.001$ \\
\hline Cohort=After 1990 & 0.557 & 0.001 & 1.835 & 0.006 & 0.611 & 0.020 \\
\hline \multicolumn{7}{|l|}{ For quadratic slope $\left(\boldsymbol{\beta}_{2 i}\right)$} \\
\hline Intercept & -0.004 & $<0.001$ & -0.002 & $<0.001$ & 0.000 & $<0.001$ \\
\hline Education $=\mathrm{JHS}$ or lower & 0.000 & 0.524 & -0.002 & $<0.001$ & -0.001 & $<0.001$ \\
\hline Education $=\mathrm{HS} /$ college & 0.000 & $<0.001$ & 0.000 & 0.138 & 0.000 & 0.260 \\
\hline Education $=U$ or higher & Reference & & & & & \\
\hline Cohort= before 1920 & -0.006 & $<0.001$ & -0.004 & 0.032 & 0.000 & 0.728 \\
\hline Cohort = 1920-1929 & -0.002 & 0.002 & 0.002 & 0.471 & 0.001 & 0.192 \\
\hline Cohort = 1930-1939 & -0.002 & $<0.001$ & 0.001 & 0.241 & 0.001 & 0.003 \\
\hline Cohort $=1940-1949$ & -0.001 & $<0.001$ & 0.002 & $<0.001$ & 0.001 & $<0.001$ \\
\hline Cohort = 1950-1959 & -0.001 & $<0.001$ & -0.002 & $<0.001$ & -0.001 & $<0.001$ \\
\hline Cohort = 1960-1969 & Reference & & & & & \\
\hline Cohort = 1970-1979 & 0.000 & 0.005 & 0.003 & $<0.001$ & 0.001 & $<0.001$ \\
\hline Cohort = 1980-1989 & 0.002 & $<0.001$ & 0.015 & $<0.001$ & 0.005 & $<0.001$ \\
\hline Cohort = After 1990 & 0.014 & $<0.001$ & 0.041 & 0.007 & 0.013 & 0.026 \\
\hline \multicolumn{7}{|l|}{ Random effects parameters } \\
\hline Intercept $\left(\boldsymbol{u}_{0 i}\right)$ & 27.765 & & 82.198 & & 11.549 & \\
\hline Linear slope $\left(\boldsymbol{u}_{1 i}\right)$ & 0.002 & & 0.083 & & 0.013 & \\
\hline Quadratic slope $\left(\boldsymbol{u}_{2 i}\right)$ & 0.000 & & 0.000 & & 0.000 & \\
\hline Residual $\left(\boldsymbol{e}_{t i}\right)$ & 0.218 & & 3.711 & & 0.601 & \\
\hline
\end{tabular}

JHS junior high school; $H S$ high school; U University 
in men but with higher weight in women. For both men and women, lower educational levels were associated with higher BMI and the disparities were found to be larger among women.

The age-related pattern for the trajectory of BMI increased from 20 to 50 years of age in men, but the pattern in women increased from 20 to 70 years of age. Women continued to have increasing BMI after age 50, perhaps due to the effect of menopause transition. During menopause transition, most women experience the physiological changes and their function of ovaries is declining, resulting in the unpredictable fluctuation of sex hormones (e.g., estrogen and progesterone). Sex hormones such as estrogen seem to have a cardio-protective effect on women, leading to reduced oxidative stress and fibrosis, and to increased angiogenesis and vasodilation [19]. Several longitudinal studies have also shown that menopause transition is related to increases in waist circumference, metabolic syndrome, and cholesterol levels [20-22]. It is important to study and understand the influence of menopause transition on the body composition and cardio-metabolic health, as this is a universal and crucial stage in the life course for all women.

We observed evident cohort effects on the trajectories of height, weight, and BMI; younger cohorts had higher values than the older cohorts. These results indicate that the historical changes in the physical and social environment might have a strong effect on body type and composition. In the older birth cohorts in Taiwan, there was a larger proportion of people who suffered from poverty and undernutrition. Since the industrialization and economic growth of Taiwan, the socioeconomic condition and nutritional status has become better and better, which has resulted in the increasing height and weight over secular time. In the youngest birth cohorts, there was probably the highest proportion of people having unhealthy eating behaviors, sedentary lifestyles, and using technologies that are conductive to obesity. Our observations regarding the cohort effects agree with previous findings from other countries and highlight that the social and physical environments that individuals are exposed to play an important role in the trajectory of BMI, in addition to biological aging $[5,6,8,23,24]$.

Furthermore, we observed a larger cohort effect for men than for women in our study population. In a study using the China Health and Nutritional Survey, the investigators showed similar findings [5]. In their final adjusted linear mixed-effects model, comparing an average 25- or 45-yearold person in 2009 versus 1991 in China, they found that the change in BMI was greater for men than for women. The authors hypothesized that occupation may cause the sex differences. More and more people have been engaged in occupations with lower levels of physical activity than before and the tendency has been stronger for men than for women $[25,26]$. We think that similar trends could be observed in Taiwan, and the findings also imply that occupational physical activity may account for a major part of total energy expenditures, particularly for men [24, 27].

We also identified a clear "social patterning" of the trajectories of BMI in our study population. Individuals with higher educational levels may have better health literacy, socio-psychological resources, and self-efficacy, and be more likely to engage in healthy behaviors to control their weight gain [28]. Thereby, we found higher educational levels were associated with lower weight and BMI among women. However, for men the educational disparity of BMI was smaller than for women and higher educational levels were even associated with higher weight among men. Similar findings were reported in other populations. In the US, Yang and colleagues [8] reported a clear educational gradient in the trajectories of BMI for women and showed that women with a college degree or more had the lowest BMI trajectory, but this gradient was less evident for men. In a comparative study between Japan and England [29], Martikainen and colleagues found that Japanese men with higher employment grades and higher educational levels had higher BMI, waist-to-hip-ratio and lower high density lipoprotein cholesterol, whereas in England higher socioeconomic status had better profiles regarding these risk factors. The social patterning observed in our population may suggest that education is a more important social determinant for cardio-metabolic health for women than for men and that there is variation among different countries and cultures in terms of educational disparities.

The major strength of the current study was that weight and height were measured objectively rather than relying on self-reporting of the participants. Many reports have collected only the self-reported data on weight and height. People tend to overreport their height and underreport their weight [30]. Another strength is that our open cohort design and study sample comprised 572,358 individuals aged between 20 and 94years who were followed up to 22 years, which provided a unique opportunity for doing life course trajectory research as the sample included people from a wide spectrum of birth cohorts.

(See figure on next page.)

Fig. 2 (A) Predicted height trajectories by education for men. Only 1920-1929, 1950-1959 and 1980-1989 birth cohorts are included for purpose of illustration. (B) Predicted height trajectories by education for women. (C) Predicted weight trajectories by education for men. (D) Predicted weight trajectories by education for women. (E) Predicted BMI trajectories by education for men. (F) Predicted BMI trajectories by education for women. $\mathrm{BMI}=$ body mass index 


\section{Men}

A



C



E

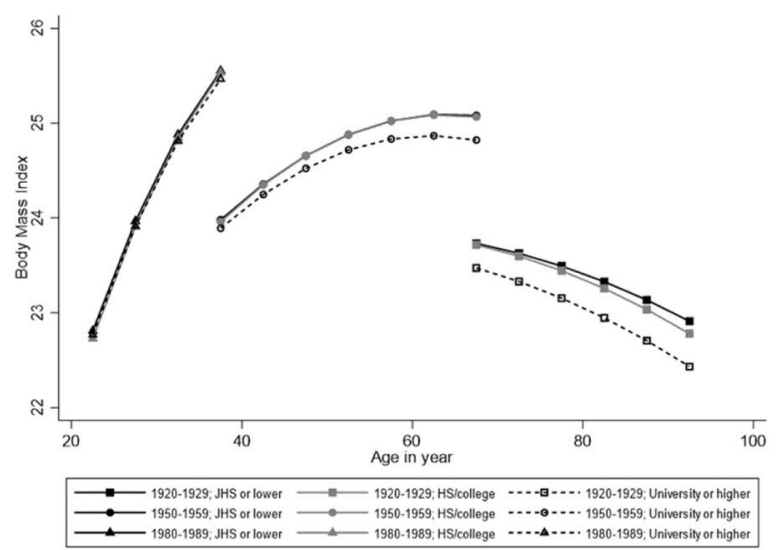

Women

B

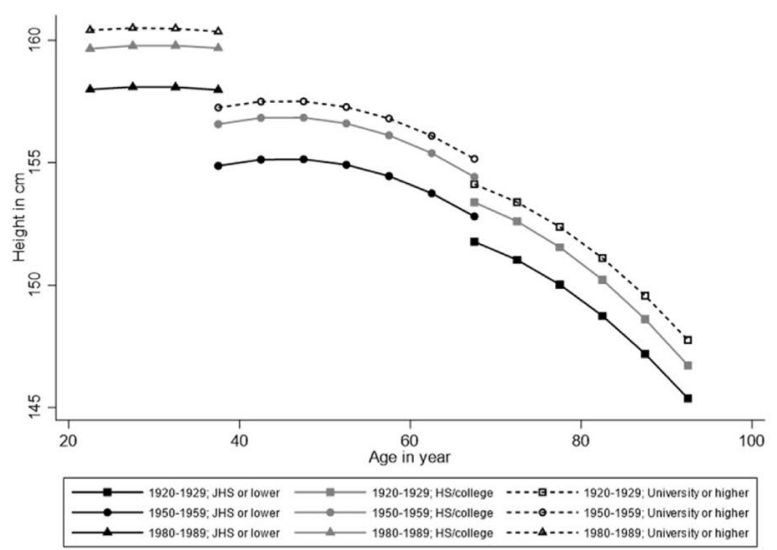

D

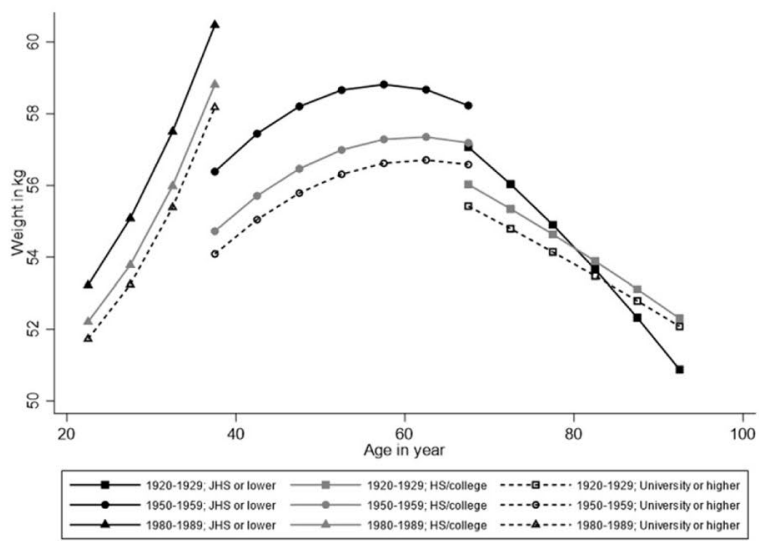

$\mathbf{F}$



Abbreviations: JHS = junior high school; $\mathrm{HS}=$ high school

Fig. 2 (See legend on previous page.) 
Nevertheless, our study was not free of limitations. People with a normal BMI may be overrepresented in the older participants of our sample, since people who were underweight, overweight or obese tended to have a higher risk of death [1]. Thereby, the trajectories of height, weight, and BMI might be subject to this selective mortality in our study. Another limitation was that we did not specifically add the period effect into our models given the model identification problems of the collinearity of age, period, and cohort effects [31]. As in the study done by Yang et al. [8], we assumed that the period effect was trivial and that we would detect the period effect through the cohort-by-age interaction terms.

\section{Conclusion}

Trends of increasing BMI are likely to result in subsequent increases in the prevalence of overweight and obesity in the population. Our study demonstrated that in Taiwan there is a birth cohort effect on the increasing BMI, particularly for men, and that there is an educational disparity for trajectories of BMI, particularly for women. These findings provide important insights to the design and implementation of interventions that address overweight and obesity; for example, we should put more emphasis on the younger cohorts at an early age and on women with lower educational levels.

\section{Abbreviations}

BMI: Body mass index; HS: High school; JHS: Junior high school; SD: Standard deviation; US: United States.

\section{Acknowledgements \\ None.}

\section{Authors' contributions}

TJW and TY conceptualized the project; TJW and TY analyzed the data; TJW and TY drafted the manuscript. All authors played an important role in interpreting the results, providing substantive feedback on the manuscript, and approved the final version.

\section{Funding}

Ministry of Science and Technology, Taiwan (110-2314-B-006-050). The funders had no roles in the design and conduct of the study.

\section{Availability of data and materials}

The datasets used and analyzed during the current study are available from the corresponding author (Prof. Tsung Yu) on reasonable request.

\section{Declarations}

Ethics approval and consent to participate

The present study was approved by the ethics board at the National Cheng Kung University in Tainan, Taiwan (A-ER-108-081) and all study procedures and methods were carried out in accordance to their guidelines. Informed consent was obtained from all participants.

\section{Consent for publication}

Not applicable.

\section{Competing interests}

The authors declare no competing interests.

\section{Author details}

${ }^{1}$ Department of Healthcare Information and Management, School of Health Technology, Ming Chuan University, Taoyuan, Taiwan. ${ }^{2}$ Department of Academic Clinical Programme, National Dental Centre, Singapore, Singapore. ${ }^{3}$ Department of Public Health, College of Medicine, National Cheng Kung University, 1 University Road, Tainan, Taiwan. ${ }^{4}$ Institute of Sociology, Academia Sinica, Taipei, Taiwan. ${ }^{5}$ Jockey Club School of Public Health and Primary Care, the Chinese University of Hong Kong, Hong Kong, SAR, China.

Received: 30 August 2021 Accepted: 10 February 2022

Published online: 28 February 2022

\section{References}

1. Bhaskaran K, et al. Association of BMI with overall and cause-specific mortality: a population-based cohort study of 3.6 million adults in the UK. Lancet Diabetes Endocrinol. 2018;6(12):944-53.

2. Juhaeri, et al. Associations of aging and birth cohort with body mass index in a biethnic cohort. Obes Res. 2003;1 1(3):426-33.

3. Baltrus PT, et al. Race/ethnicity, life-course socioeconomic position, and body weight trajectories over 34 years: the Alameda County study. Am J Public Health. 2005;95(9):1595-601.

4. Clarke P, et al. Social disparities in BMI trajectories across adulthood by gender, race/ethnicity and lifetime socio-economic position: 1986-2004. Int J Epidemiol. 2009;38(2):499-509.

5. Jaacks LM, et al. Age, period and cohort effects on adult body mass index and overweight from 1991 to 2009 in China: the China health and nutrition survey. Int J Epidemiol. 2013;42(3):828-37.

6. Caman OK, et al. Longitudinal age-and cohort trends in body mass index in Sweden--a 24-year follow-up study. BMC Public Health. 2013;13:893.

7. Murayama $\mathrm{H}$, et al. Socioeconomic status and the trajectory of body mass index among older Japanese: a Nationwide cohort study of 1987-2006. J Gerontol B Psychol Sci Soc Sci. 2016;71(2):378-88.

8. Yang YC, et al. Life-course trajectories of body mass index from adolescence to old age: racial and educational disparities. Proc Natl Acad Sci U S A. 2021;118(17).

9. Lee JM, et al. Getting heavier, younger: trajectories of obesity over the life course. Int J Obes. 2010;34(4):614-23.

10. Johnson W, et al. How has the age-related process of overweight or obesity development changed over time? Co-ordinated analyses of individual participant data from five United Kingdom birth cohorts. PLoS Med. 2015;12(5):e1001828 discussion e1001828.

11. Kant AK, Graubard BI. 40-year trends in meal and snack eating behaviors of American adults. J Acad Nutr Diet. 2015;115(1):50-63.

12. Gordon-Larsen P, Nelson MC, Popkin BM. Longitudinal physical activity and sedentary behavior trends: adolescence to adulthood. Am J Prev Med. 2004:27(4):277-83.

13. Paeratakul $\mathrm{S}$, et al. The relation of gender, race and socioeconomic status to obesity and obesity comorbidities in a sample of US adults. Int J Obes Relat Metab Disord. 2002;26(9):1205-10.

14. Selya, R.M., Development and demographic change in Taiwan. 2004: World Scientific.

15. Wu X, et al. Cohort profile: the Taiwan MJ cohort: half a million Chinese with repeated health surveillance data. Int J Epidemiol. 2017:46(6):1744-1744g.

16. Bo Y, et al. Reduced ambient PM2.5, better plasma glucose level, and decreased risk of type 2 diabetes in adults: a longitudinal cohort study. Am J Epidemiol. 2021.

17. YuT, et al. Adiposity and risk of death: a prospective cohort study of 463,002 adults. Clin Nutr. 2021:40(4):1932-41.

18. Cnaan A, Laird NM, Slasor P. Using the general linear mixed model to analyse unbalanced repeated measures and longitudinal data. Stat Med. 1997;16(20):2349-80.

19. Knowlton AA, Lee AR. Estrogen and the cardiovascular system. Pharmacol Ther. 2012;135(1):54-70. 
20. Sowers $\mathrm{M}$, et al. Changes in body composition in women over six years at midlife: ovarian and chronological aging. J Clin Endocrinol Metab. 2007;92(3):895-901.

21. Janssen I, et al. Menopause and the metabolic syndrome: the study of Women's health across the nation. Arch Intern Med. 2008;168(14):1568-75.

22. Derby $C A$, et al. Lipid changes during the menopause transition in relation to age and weight: the study of Women's health across the nation. Am J Epidemiol. 2009:169(11):1352-61.

23. Wang $W-C$. Transformations of employment and occupation patterns in Taiwan's transition to an information society. Chin J Communication, 2011;4(4):450-74.

24. Deptartment of household registration, Ministry of the Interior, and republic of China (Taiwan), Popul Pol Data Collection 2020.

25. Monda KL, et al. China's transition: the effect of rapid urbanization on adult occupational physical activity. Soc Sci Med. 2007;64(4):858-70

26. Hu GC, et al. Occupational versus leisure-time physical activity in reducing cardiovascular risks and mortality among ethnic Chinese adults in Taiwan. Asia Pac J Public Health. 2014;26(6):604-13.

27. Liou YM. Patterns of physical activity and obesity indices among whitecollar men in Taiwan. J Nurs Res. 2007;15(2):138-46.

28. Galobardes B, et al. Indicators of socioeconomic position (part 1). J Epidemiol Community Health. 2006;60(1):7-12.

29. Martikainen $P$, et al. Socioeconomic differences in behavioural and biological risk factors: a comparison of a Japanese and an English cohort of employed men. Int J Epidemiol. 2001;30(4):833-8.

30. Stewart AW, et al. Underestimation of relative weight by use of selfreported height and weight. Am J Epidemiol. 1987;125(1):122-6.

31. Kupper LL, et al. Statistical age-period-cohort analysis: a review and critique. J Chronic Dis. 1985;38(10):811-30.

\section{Publisher's Note}

Springer Nature remains neutral with regard to jurisdictional claims in pub-

lished maps and institutional affiliations.

- fast, convenient online submission

- thorough peer review by experienced researchers in your field

- rapid publication on acceptance

- support for research data, including large and complex data types

- gold Open Access which fosters wider collaboration and increased citations

- maximum visibility for your research: over $100 \mathrm{M}$ website views per year

At BMC, research is always in progress.

Learn more biomedcentral.com/submissions 